\title{
When is a vesicle not just a vesicle: mitochondrial spheroids and mitochondrial autophagosomes
}

\author{
Katherine L Cook ${ }^{1 *}$, David R Soto-Pantoja ${ }^{2}$, Lu Jin ${ }^{1}$, Mones Abu-Asab ${ }^{3}$ and Robert Clarke ${ }^{1 *}$
}

\section{To the Editor:}

The commentary by Ding and Eskelinen "Do mitochondria donate membrane to form autophagosomes or undergo remodeling to form mitochondrial spheroids?" on our recently published manuscript raises several important points that we wish to address. To do so, we here include several key experiments to clarify further that the mitochondrial vesicles observed in Cook et al. are likely to be autophagosomes [1], rather than "mitochondrial spheroids".

Ding et al. previously showed that when mouse embryonic fibroblasts are treated with the mitochondrial de-coupler agent CCCP, a structure they called a "mitochondrial spheroid" develops. These authors concluded that the spheroids are not autophagosomes because they still form in $\mathrm{ATG5}^{-/-}$and $\mathrm{ATG7}^{-1-}$ embryonic fibroblasts [2]. However, autophagy is a complex pathway involving multiple mechanisms of activation. While ATG5 and ATG7 can play an important role in autophagosome formation, they are not obligatory in all cases. For example, autophagy can be activated in an ATG5/ATG7 independent manner involving ULK1 and Rab9 [3].

Ding and Eskelinen's criticism of our study is the lack of electron microscopy (EM) images from cells with inhibited autophagy. We now show EM images from LCC9 cells transfected with ATG7 siRNA (Figure 1). We confirmed that ATG7 knockdown inhibits autophagy as shown by a reduction of LC3-II formation and an accumulation of p62 (Figure 1A). Furthermore, EM images indicate that ATG7 knockdown reduces autophagosome formation approximately by $50 \%$ (Figure 1D). Knockdown of ATG7 by RNAi also resulted in the accumulation of mitochondria as measured by COXIV (Figure 1B). We also observed increased mitochondria number (average 13.8 mitochondria per EM image versus 9.1 mitochondria per EM image) in ATG7 siRNA transfected cells when compared with control transfected cells. Taken together, these data imply that autophagy is a major pathway for

\footnotetext{
* Correspondence: klc74@georgetown.edu; clarker@georgetown.edu 'Department of Oncology and Lombardi Comprehensive Cancer Center, Georgetown University Medical Center, Washington, DC 20057, USA Full list of author information is available at the end of the article
}

the recycling of mitochondria in antiestrogen resistant breast cancer cells. Moreover, inhibiting autophagy reduced the formation of mitochondrial vesicles, providing further evidence that the vesicles formed by the mitochondria membranes are likely to be autophagosomes (Figure $1 \mathrm{C}$ and $1 \mathrm{E}$ ).

In our previous publication, we demonstrated by immuno-gold electron microscopy, that mitochondria form vesicles that stain positive for LC3, suggesting that these vesicles are likely to be autophagosomes [1]. Microtubule associated protein 1 light chain 3 (MAPLC3, LC3) is lipidated and incorporated into the autophagosomal membrane and is often used as a means to identify appropriate structures as autophagosomes and not lysosomes [4]. ATG7 can play a critical role in LC3 processing and autophagosome formation. Coupled with our new data included here, showing that ATG7 inhibition prevented mitochondrial vesicle formation, these observations further support our original conclusion that the vesicles are most likely to be autophagosomes. We also showed that the mitochondria forming autophagosomes stain positive for parkin. Quantification of parkin immuno-gold EM showed elevated levels of parkin in the cytosol and also increased parkin labeling on mitochondria-forming vesicles. These data imply that the mitochondrial vesicles represent a novel form of mitophagy. Moreover, inhibition of parkin by RNAi prevented an ICI (the antiestrogen known as Fulvestrant or Faslodex)mediated reduction of mitochondrial content, supporting a role of parkin in mitochondrial clearance [1].

Ding and Eskelinen discuss an interesting question on the role of parkin as a tumor suppressor. While we agree that in some cancers parkin may be a tumor suppressor [5], we find elevated endogenous levels of parkin in antiestrogen resistant LCC9 breast cancer cell lines when compared with their endocrine sensitive parental control cells (LCC1; Figure 2). Parkin was also shown to promote various cytoprotective cell signaling pathways including stabilization of the pro-survival BCL2 family member, MCL-1 [6]. BCL2 signaling is critically important to the maintenance of the antiestrogen resistance phenotype 


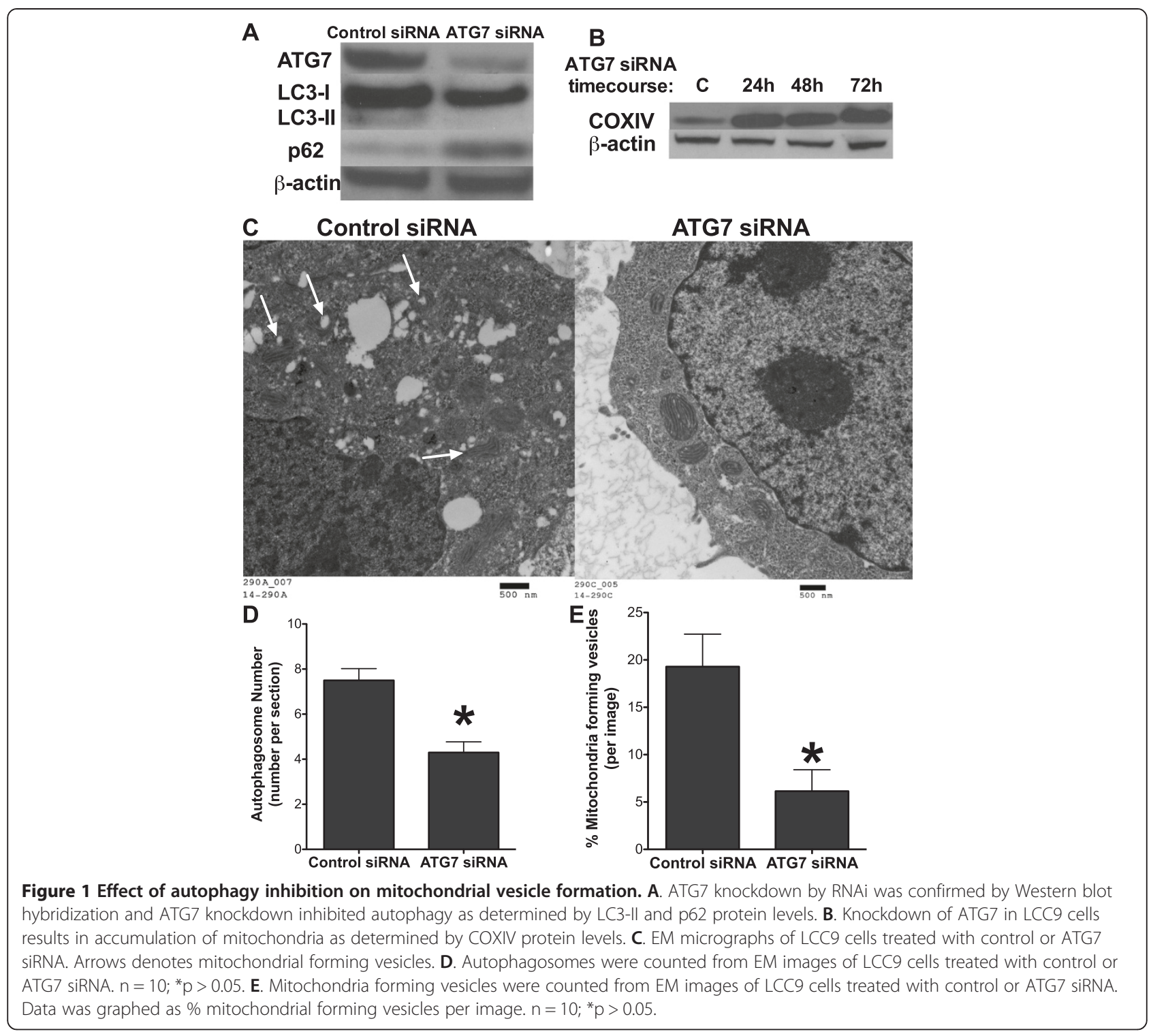

in ER + breast cancer cells [7-9], highlighting a possible pro-tumorigenic role of parkin in breast cancer. However, publically available human ER + breast cancer data sets are inconclusive on the role of parkin in ER + breast cancer survival (Figure 2B and 2C), where the results differ depending on the data sets analyzed $[10,11]$. We also showed in our original manuscript that knockdown of PINK1 restores antiestrogen sensitivity to LCC9 breast cancer cells, further indicating a possible role of mitophagy in maintaining an endocrine therapy resistant phenotype [1]. PINK1 is a mitochondrial serine/theorinine kinase involved in the recruitment of parkin to the mitochondrial membrane. While PINK1 is predominately a mitochondrial protein, multiple reports have identified a cytosolic version of PINK1 $[12,13]$. As we do not know the precise role of cytosolic PINK1 versus mitochondrial PINK1 in ER + breast cancer, we cannot exclude the possibility of both cytosolic and mitochondrial PINK1 contributing to the antiestrogen resistance phenotype. Further experimentation is needed to determine the role of parkin, PINK1, and mitophagy in antiestrogen resistance and breast cancer survival, which was outside the scope of our original short report.

Using a mouse embryonic fibroblast cell line, a previous study by Hailey et al. showed that mitochondria donate outer membrane material to form autophagosomes under serum starvation [14]. These authors showed that the mitochondrial membrane formation of autophagosomes is an ATG5 dependent and mitofusin-2 dependent process. Mitofusin-2 was critical to maintain the endoplasmic reticulum/mitochondrial connection necessary for mitochondrial autophagosome formation, and deletion of mitofusin-2 inhibited their formation [14]. The mitochondrial spheroid formation process illustrated in Ding et al., 
A

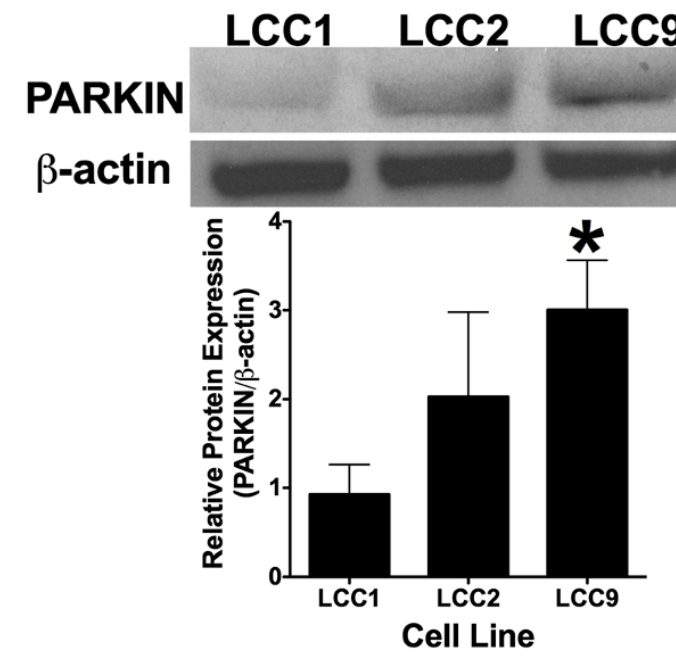

\begin{tabular}{|c|c|c|c|}
\hline $\begin{array}{l}\text { Breast Cancer Data } \\
\text { Set }\end{array}$ & p value & $\begin{array}{l}\text { PARK2 Fold } \\
\text { change }\end{array}$ & $\begin{array}{l}\text { Higher PARK2 } \\
\text { expression }\end{array}$ \\
\hline Desmedt, 2007 & .01 & 1.4 & $\begin{array}{l}\text { ER+ breast tumors } \\
\text { that reoccur }\end{array}$ \\
\hline Sotiriou & .02 & 1.1 & $\begin{array}{l}\text { ER+ breast tumors } \\
\text { that never reoccurs }\end{array}$ \\
\hline
\end{tabular}
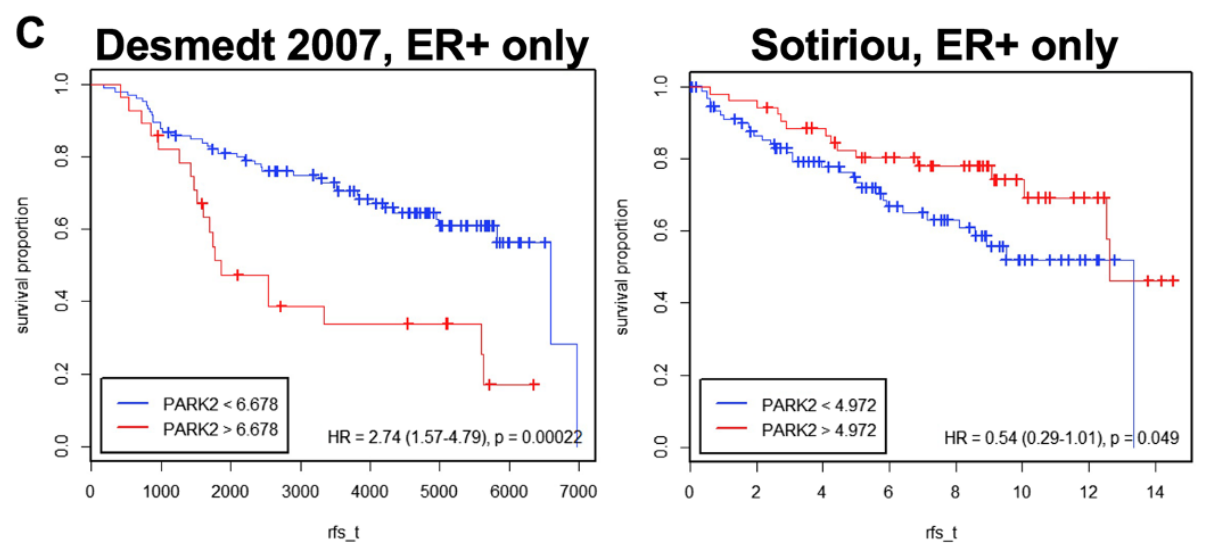

Figure 2 Parkin expression in ER + breast cancer. A. Parkin protein levels in ER + breast cancer cell lines as determined by Western blot hybridization. B. Parkin expression in ER + breast tumors that reoccur versus tumors that never reoccur. $\mathbf{C}$. Parkin expression and ER + breast cancer survival in human data sets $[10,11]$.

also using a mouse embryonic fibroblast cell line, indicated that the "mitochondrial spheroid" formation induced by the mitochondrial decoupling agent CCCP, is dependent on mitofusin-1 and mitofusin-2. The work by Ding et al. and Hailey et al. highlight the importance of mitofusin proteins in mitochondrial vesicle formation. While our original short report did not explore the effect of mitofusins, we now include data to begin to address their role. Mitofusin-1 and -2 levels do not change in LCC9 cells when treated with $100 \mathrm{nM}$ ICI or $10 \mu \mathrm{M}$ Imatinib for 72 hours (Figure 3A), the drugs utilized in Cook et al. to increase mitochondrial autophagosome formation. Knockdown of mitofusin-1 by RNAi had no effect on autophagosome formation as measured by LC3-II formation and p62 degradation (Figure 3B). Furthermore, inhibition of mitofusin-1 had no effect on parkin levels (Figure 3B), suggesting that there was no reciprocal relationship between parkin and mitofusins in human ER + breast cancer cells, unlike the report using mouse embryonic fibroblasts by Ding et al.

Consideration of cellular context is usually critical in the interpretation of much cell and molecular biologic data. Cellular signaling in cancer is often altered to favor proliferation and survival. While Ding and Eskelinen questioned our study due to differences they observed between parkin and mitofusin regulation, it would not 


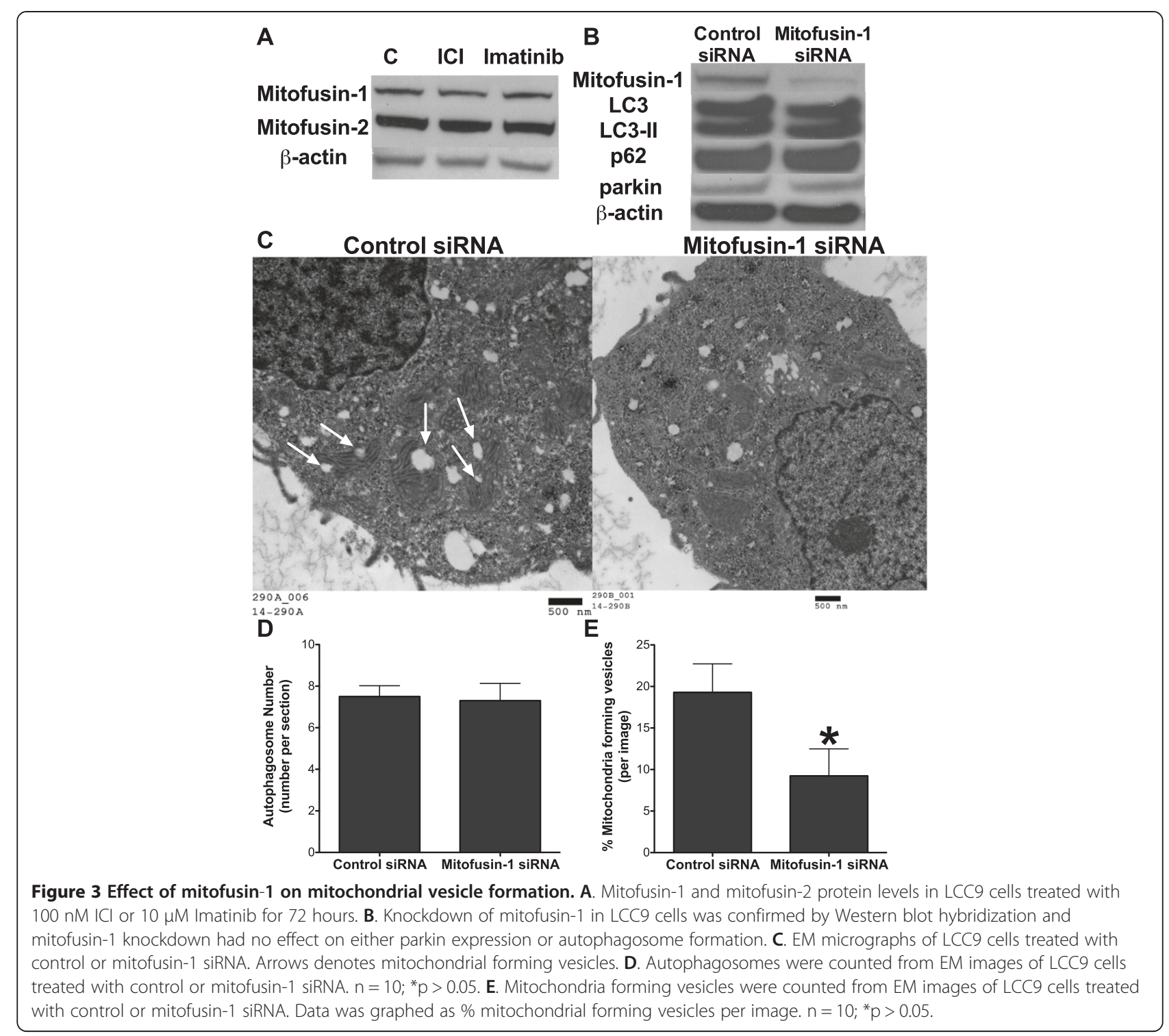

be unusual for mitochondrial vesication to be controlled differently between a human ER + breast cancer cell line and a mouse embryonic fibroblast cell line.

The observations from western hybridizatons were confirmed in EM images taken from LCC9 cells transfected with mitofusin-1 siRNA (Figure 3C). Quantification of EM micrographs indicates that mitofusin-1 inhibition had no effect on autophagosome number (Figure 3D) when compared with control siRNA transfected cells. However, mitofusin-1 knockdown inhibited mitochondrial vesicle formation (Figure 3E). These data suggest that mitofusin1 plays a critical role in the development of mitochondrial autophagosomes with no effect on the classical autophagosome formation pathways. These new data, coupled with our previous data, strongly support our original interpretation that, in ER + breast cancer cells, mitochondria donate their cellular membrane material to form autophagosomes and that this occurs in an ATG7 and mitofusin-1 dependent manner.

Finally, we appreciate that this is a controversial area and that others may choose to arrive at different conclusions from the same data. We appreciate the opportunity the journal has provided to contrast our interpretations with those of Ding and Eskelinen. We also look forward to the publication of additional studies that may better delineate the nature and physiological relevance of both autophagosomes and what appear to be the closely related "mitochondrial spheroid" structures.

\section{Author details}

${ }^{1}$ Department of Oncology and Lombardi Comprehensive Cancer Center, Georgetown University Medical Center, Washington, DC 20057, USA.

'Laboratory of Pathology, National Cancer Institute, National Institutes of Health, Bethesda, MD 20892, USA. ${ }^{3}$ National Eye Institute, National Institutes of Health, Bethesda, MD 20892, USA. 


\section{References}

1. Cook KL, Soto-Pantoja DR, Abu-Asab M, Clarke PA, Roberts DD, Clarke R: Mitochondria directly donate their membrane to form autophagosomes during a novel mechanism of parkin-associated mitophagy. Cell Biosci 2014, 4(1):16.

2. Ding WX, Guo F, Ni HM, Bockus A, Manley S, Stolz DB, Eskelinen EL, Jaeschke $\mathrm{H}$, Yin XM: Parkin and mitofusins reciprocally regulate mitophagy and mitochondrial spheroid formation. J Biol Chem 2012 287(50):42379-42388.

3. Nishida Y, Arakawa S, Fujitani K, Yamaguchi H, Mizuta T, Kanaseki T, Komatsu M, Otsu K, Tsujimoto Y, Shimizu S: Discovery of Atg5/Atg7-independent alternative macroautophagy. Nature 2009, 461(7264):654-658.

4. Klionsky DJ, Abdalla FC, Abeliovich H, Abraham RT, Acevedo-Arozena A, Adeli K, Agholme L, Agnello M, Agostinis P, Aguirre-Ghiso JA, Ahn HJ, Ait-Mohamed O, Ait-Si-Ali S, Akematsu T, Akira S, Al-Younes HM, Al-Zeer MA, Albert ML, Albin RL, Alegre-Abarrategui J, Aleo MF, Alirezaei M, Almasan A, Almonte-Becerril M, Amano A, Amaravadi R, Amarnath S, Amer AO, Andrieu-Abadie N, Anantharam V, et al: Guidelines for the use and interpretation of assays for monitoring autophagy. Autophagy 2012, 8(4):445-544.

5. Inzelberg R, Jankovic J: Are Parkinson disease patients protected from some but not all cancers? Neurology 2007, 69(15):1542-1550.

6. Ekholm-Reed S, Goldberg MS, Schlossmacher MG, Reed SI: Parkin-dependent degradation of the F-box protein Fbw7beta promotes neuronal survival in response to oxidative stress by stabilizing Mcl-1. Mol Cell Biol 2013, 33(18):3627-3643.

7. Schwartz-Roberts JL, Shajahan AN, Cook KL, Warri A, Abu-Asab M, Clarke R. GX15-070 (obatoclax) induces apoptosis and inhibits cathepsin D- and L-mediated autophagosomal lysis in antiestrogen-resistant breast cancer cells. Mol Cancer Ther 2013, 12(4):448-459.

8. Nehra R, Riggins RB, Shajahan AN, Zwart A, Crawford AC, Clarke R: BCL2 and CASP8 regulation by NF-kappaB differentially affect mitochondrial function and cell fate in antiestrogen-sensitive and -resistant breast cancer cells. FASEB J 2010, 24(6):2040-2055.

9. Crawford AC, Riggins RB, Shajahan AN, Zwart A, Clarke R: Co-inhibition of $B C L-W$ and $B C L 2$ restores antiestrogen sensitivity through BECN1 and promotes an autophagy-associated necrosis. PLoS One 2010, 5(1):e8604.

10. Sotiriou C, Wirapati P, Loi S, Harris A, Fox S, Smeds J, Nordgren H, Farmer P, Praz V, Haibe-Kains B, Desmedt C, Larsimont D, Cardoso F, Peterse H, Nuyten D, Buyse M, Van de Vijver MJ, Bergh J, Piccart M, Delorenzi M: Gene expression profiling in breast cancer: understanding the molecular basis of histologic grade to improve prognosis. J Natl Cancer Inst 2006, 98(4):262-272.

11. Desmedt C, Piette F, Loi S, Wang Y, Lallemand F, Haibe-Kains B, Viale G, Delorenzi M, Zhang Y, D'Assignies MS, Bergh J, Lidereau R, Ellis P, Harris AL, Klijn JG, Foekens JA, Cardoso F, Piccart MJ, Buyse M, Sotiriou C, Consortium T: Strong time dependence of the 76-gene prognostic signature for node-negative breast cancer patients in the TRANSBIG multicenter independent validation series. Clin Cancer Res 2007, 13(11):3207-3214.

12. Takatori S, Ito G, Iwatsubo T: Cytoplasmic localization and proteasomal degradation of N-terminally cleaved form of PINK1. Neurosci Lett 2008, 430(1):13-17.

13. Haque ME, Thomas KJ, D'Souza C, Callaghan S, Kitada T, Slack RS, Fraser P, Cookson MR, Tandon A, Park DS: Cytoplasmic Pink1 activity protects neurons from dopaminergic neurotoxin MPTP. Proc Natl Acad Sci U S A 2008, 105(5):1716-1721.

14. Hailey DW, Rambold AS, Satpute-Krishnan P, Mitra K, Sougrat R, Kim PK, Lippincott-Schwartz J: Mitochondria supply membranes for autophagosome biogenesis during starvation. Cell 2010, 141(4):656-667.

doi:10.1186/2045-3701-4-66

Cite this article as: Cook et al: When is a vesicle not just a vesicle: mitochondrial spheroids and mitochondrial autophagosomes. Cell \& Bioscience 2014 4:66.

\section{Submit your next manuscript to BioMed Central and take full advantage of:}

- Convenient online submission

- Thorough peer review

- No space constraints or color figure charges

- Immediate publication on acceptance

- Inclusion in PubMed, CAS, Scopus and Google Scholar

- Research which is freely available for redistribution

Submit your manuscript at www.biomedcentral.com/submit
Biomed Central 